\title{
Profesyonel futbolcularda alt ekstremite kas kuvveti asimetrisi, denge ve ayak bileği yaralanma riski arasındaki ilişkinin incelenmesi
}

\author{
Rıdvan SEYHAN ${ }^{1}$, Eren TiMURTAŞ ${ }^{2}$, M. Gülden POLAT ${ }^{3}$
}

Amaç: Bu çalışmada profesyonel futbolcularda alt ekstremite kas kuvvet asimetrisi, dinamik denge ve ayak bileği yaralanma riski arasındaki ilişkinin incelenmesi amaçlandı.

Yöntem: Çalıșmaya 20 profesyonel erkek futbolcu dahil edildi. Bilateral dinamik dengeyi değerlendirmek için $Y$ denge testi kullanıldı. Alt ekstremiteye ait bilateral kalça fleksör, kalça ekstansör, kalça abduktör, kalça adduktör, diz fleksör, diz ekstansör, ayak bileği dorsifleksör, ayak bileği plantar fleksör, ayak bileği evertörve ayak bileği invertör kas gruplarının maksimal izometrik kontraksiyonu değerlendirmek için Groinbar sistemi kullanıldı.

Bulgular: Çalışmaya dahil edilen oyuncuların yaş ortalaması $27,80 \pm 5,80$ yıl ve vücut kütle indeksi ortalaması $24,04 \pm 1,55$ $\mathrm{kg} / \mathrm{m}^{2}$ olarak bulundu. Her iki ayak bileği dorsifleksör ve plantarfleksör kas grupları arasındaki oran ile denge testinde anteriorposterior bilateral fark arasında istatistiksel açıdan anlamlı sonuç elde edildi (Sol: $p=0,012$, rho=-0,552, Sağ: $p=0$, rho=0,727). Anterior-posterior denge farkının yaralanma riski açısından değerlendirildiğinde; kalça abduktör ve adduktör kas grupları arasındaki oran ile ayak bileği yaralanma riski açısından anlamlı korelasyon bulundu (Sol: $p=0,026$, rho $=-0,498$, Sağ: $\mathrm{p}=0,006$, rho=-0,595).

Sonuç: Profesyonel futbolcularda alt ekstremiteye ait plantarfleksör/dorsifleksör ve adduktör/abduktör kas gruplarının izometrik kuvvet oranının ve bilateral plantar fleksör kuvvet asimetrisinin dinamik denge ve ayak bileği yaralanma riskiyle ilişkili olduğu bulundu.

Anahtar Kelimeler: Futbol, Postüral denge, Kas kuvveti.

Relationships between lower extremity muscle strength asymmetry, balance and ankle injury risk in professional football players

Purpose: In this study, it was aimed to determine the relationships between lower extremity muscle strength asymmetry, dynamic balance and ankle injury risk in professional football players.

Method: The participants of the study comprised twenty professional male soccer players. Y Balance Test was used to evaluate bilateral dynamic balance. Groinbar system was used to evaluate maximal isometric contraction of bilateral hip flexor, hip extensor, hip abductor, hip adductor, knee flexor, knee extensor, ankle dorsiflexor, ankle plantar flexor, ankle evertor and ankle muscle groups.

Results: The mean age of the players included in the study was $27,80 \pm 5,80$ years and the mean body mass index was $24,04 \pm 1,55 \mathrm{~kg} / \mathrm{m}^{2}$. It was found that there was statistically meaningful result between ratio of bilateral dorsiflexors/plantar flexors muscle groups and anterior-posterior bilateral difference in balance test (Left: $p=0,012$, rho $=-0,552$, Right: $p=0$, rho=$0,727)$. It was found that there was meaningful correlation between bilateral force asymmetry of plantar flexors and anteriorposterior bilateral difference. $\left(p=0,038, r_{0}=0,466\right)$. In addition, when the anterior-posterior balance difference is evaluated in terms of injury risk; a meaningful correlation was found between the ratio of hip abductor and adductor muscle groups, and the risk of ankle injury. (Left: $p=0,026$, rho $=-0,498$, Right: $p=0,006$, rho $=-0,595$ ). Conclusion: It was found that bilateral plantar flexor strength asymmetry and the isometric strength ratio of plantar flexor / dorsiflexor and adductor/abductor muscle groups of the lower extremity in professional football players had relationships with dynamic balance and ankle injury risk. Keywords: Football, Postural balance, Muscle strength.

1: Istanbul Başakșehir Football Club, Istanbul, Turkey.

2: Marmara University, Teaching Assistant of Physiotherapy and Rehabilitation Department, Istanbul, Turkey.

3: Marmara University, Vice-Dean of Faculty of Healt Science, Istanbul, Turkey.

Corresponding Author: Rıdvan Seyhan: r.seyhan@hotmail.com

ORCID IDs (order of authors): 0000-0002-8776-7057; 0000-0001-9033-4327; 0000-0002-9705-9740

Received: November 4, 2020. Accepted: February 22, 2021.

DOI: 10.15437/jetr.820854 
$\mathrm{F}$ utbol, tek taraflı dengenin gerektirdiği aksiyonları içeren birçok faktörün etkilediği bir spordur. ${ }^{1}$ Futbolda iyi bir denge yüksek performans işaretidir ve futbolcunun oyun içindeki hareketlerinde önemli rol oynar. Maç esnasında ani yön değiştirmeler, pas verme, topa ayakla ivme verip rakibi geçmek ve kaleye şut atmak gibi hareketlerde ağırlık merkezini korumak ve dengeyi başarılı bir şekilde sürdürmek oldukça önemlidir. ${ }^{2}$ Oyuncu topsuz olarak yön değiştirirken, pas ve şut esnasında doğru destek pozisyonu alırken, topla yön değiştirirken, topu rakipten uzağa sürerken veya rakipten kaçırırken vücut ağırlı̆̆ını değiştirecektir. $\mathrm{Bu}$ da yeni pozisyonlara hızlı bir geçişi ve beklenmeyen durumlara hızlı adaptasyonları gerektirir. ${ }^{3}$

Birçok futbol oyuncusu topa vurmak için sağ ya da sol ayağını kullanır. Bu nedenle dominant ve non-dominant bacaktaki denge ve kuvvet asimetrileri veya agonist ve antagonist kaslar arasındaki resiprokal kuvvet oranları, özellikle futbolcuların dinamik hareketleri boyunca önemli bir rol oynar.,45 Yapılan bir çalışmada, denge çalışmaları ile agonist ve antagonist ko-kontraksiyonun kısa süreli periyodlarla gerçekleşerek daha hızlı gerilip kasıldığını ve eklemlerin böylece yaralanmalardan korunduğunu bulunmuştur. ${ }^{6}$ Futbolda yaralanmaları önlemede, dinamik dengenin değerlendirilmesi yaralanma riskinin saptanması açısından önem taşımaktadır. ${ }^{7}$

Futbol oyunu çok fazla dayanıklılık gerektiren bir spor dalı olmasına rağmen, aynı zamanda optimal kas gücü gerektirir. ${ }^{8}$ Özellikle alt ekstremite kas kuvveti sprint, sıçrama, yön değiştirme, pas, şut gibi spesifik hareketlerde önemlidir. ${ }^{9}$ Azalmış kas kuvveti spor performansinin azalmasina ve sporcunun kaslarında yaralanmaya neden olabilir. ${ }^{10}$ Yapılan birçok çalışmada kas kuvveti ya da kuvvet dengesizliğinin ayak bileği ve diz yaralanmaları için risk oluşturduğunu göstermiştir. ${ }^{11} \mathrm{Bu}$ yönden bakıldığında, fonksiyonel parametrelerin değerlendirilmesi yaralanmaların önlenmesi için geliştirilen programların temelini oluşturmaktadır. ${ }^{12}$

Literatürde, futbolcularda alt ekstremite kas kuvveti ve dinamik denge arasındaki ilişki henüz saptanmamıştır. ${ }^{13}$ Ancak birçok çalışma, sporcuların denge ve kuvvet yetersizliğinin yaralanmalara yol açabileceğini ve bunların değerlendirilmesiyle yaralanma riskinin saptanabileceğini vurgulamıştır. ${ }^{14}$ Bazı çalışmalarda kuvvet ve dinamik denge birbirinden farklı bağımsız parametreler olarak değerlendirilmiştir. ${ }^{15}$ Spesifik denge, izometrik duruşu sürdürme becerisi olarak tanımlanmış olmasında rağmen; yapılan çalışmalarda profesyonel futbolcularda izometrik kuvvet ile dinamik denge arasındaki ilişkiyi inceleyen bir çalışma bulunmamaktadır. Bir çalışmada genç elit futbolcularda dinamik denge ile izometrik kuvvet değerlendirilmiş ancak yaralanmalarla ilişkisi incelenmemiştir. ${ }^{16}$

Bu çalışmanın amacı, profesyonel futbolcularda alt ekstremite izometrik kuvvet asimetrisiyle dinamik denge ve ayak bileği yaralanma riski arasındaki ilişkiyi incelemek idi.

\section{YÖNTEM}

Tanımlayıcı araştırma olarak planlanan çalışmama için, Marmara Üniversitesi Sağlık Bilimleri Fakültesi Girişimsel Olmayan Etik Kurulu tarafindan 29.11.2018 tarihinde 43 protokol numarası ile etik onay alındı. Calışmanın yapıldığı Türkiye Süper Lig’inde yer alan İstanbul Başakşehir Futbol Kulübü'nden 2018/11-15 sayll kurum izni alındı. Çalışmaya, kulübün A takımında yer alan kaleci pozisyonu dışındaki bütün oyuncular dahil edildi.

Kaleciler saha oyuncularına göre farklı hareket modelleri gerçekleştirdiklerinden dolayı çalışmaya dahil edilmedi. Kaleciler dışında kalan oyunculardan son 6 ayda 4 haftadan uzun süren sakatlığ oyuncular dahil edilmedi. Değerlendirmenin yapıldığı dönemde rehabilitasyon sürecinde olan veya rehabilitasyon sürecinden yeni çıkmış 4 oyuncu dahil edilmedi. Çalışmaya dahil edilen 18-35 yaş arası 20 profesyonel erkek futbolcu, düzenli idmanın yapıldığı devre arası kamp süresince değerlendirildi. Oyuncular, çalışma prosedürleri ile ilgili bilgilendirilmiş olup; bilgilendirilmiş onam formunu imzaladıktan sonra çalışmaya alındı.

\section{Değerlendirme}

Çalışmaya dahil edilen oyuncuların yaş, boy, kilo ve geçmiş sakatlık bilgileri kaydedildi. Oyunculara sağlık ekibi tarafından düzenli yapılan 0-10 arasında puanlanan ağrı, yorgunluk, uyku kaliteleri ile ilgili sübjektif 
sorulardan, alt ekstremiteye ait termal kamera takiplerinden ve kalp hızı değişkenliğinin ölçülmesinden elde edilen verilere göre yorgunluğu veya ağrısı olmayan oyuncular değerlendirildi. Toparlanma ölçümlerinde yorgunluğu veya ağrısı tespit edilen oyuncuların değerlendirmesi, yorgunluğun veya ağrının olmadığı bir sonraki ölçüme kadar ertelendi. Fizyoterapist eşliğinde her bir oyuncu 10 dakika bisiklet ve 5 dakika dinamik germeden oluşan ısınma programını yaptıktan sonra 3 dakika dinlendirildi. Daha sonra denge testi ve ardından maksimal izometrik kontraksiyon testleri fizyoterapist tarafindan yapildı.

\section{Y Denge Testi}

Oyuncuların dinamik dengeleri $\mathrm{Y}$ denge testi (Modified Star Excursion Balance Test, SEBT) ile değerlendirildi (Şekil 1). Test üzeri $\mathrm{cm}$ cinsinden mesafe işaretli, öndeki boru (anterior) ile diğer boruların (posterior-medial ve posterior-lateral) $135^{\circ}$, arkadaki borularm ise $90^{\circ}$ açı yaptığı üç borudan oluşan $\mathrm{Y}$ denge test kiti (Functional Movement Systems, Amerika Birleşik Devletleri) üzerinde yapıldı.. ${ }^{17}$

Değerlendirme için oyuncunun hafif giysilerle ve ayaklarının çılak olduğu durumda testin nasıl yapılacağı gösterildi ve her 3 yöne deneme şansı verildi. Test edilecek ekstremite merkezdeki platform üzerinde, topuk test sirasinda tam temasta, parmaklar kırmızı çizginin arkasında, eller tüm test sırasında kalçada olacak şekilde pozisyonlandı. Oyunculardan, hareketli platformu destek almadan parmağının ucuyla iterek götürebildiği en uzak noktaya itmesi ve dengesi bozulmadan ve yere dokunmadan başlangic pozisyonuna dönmesi istendi.

Test yapım siralaması önce sağ-sol anterior yöne, sonra sağ-sol posteromedial yöne ve en son sağ-sol posterolateral yöne gerçekleştirildi. Test sırasındaki yönlerden herhangi birinde hata olması durumunda tekrarlandı. Hareketli platformun itildiği mesafe her yöne $3 \mathrm{kez}$ tekrarlandı ve ortalaması cm cinsinden kaydedildi. ${ }^{18} \mathrm{Her}$ bir yöndeki sağ ve sol değerlerin arasındaki farklar hesaplandı. Anterior-posterior farkının $4 \mathrm{~cm}$ 'den fazla çıkması sakatlık riski olarak kabul edildi. ${ }^{19,20}$

Groinbar İzometrik Kas Testi

Taşınabilir kuvvet değerlendirme sistemi olan Groinbar (Vald Performance, Queensland, Avustralya), ölçümü yapan kişiye ve test

yöntemine dayalı olmayan; standardize edilmiş, her iki bacak arasında eş zamanlı ölçüm yapabilen bir sistemdir (Şekil 2).

Çalışmamızda alt ekstremiteye ait kas gruplarından; kalça adduktör (KADD), kalça abduktör (KABD), kalça ekstansör (KE), kalça fleksör (KF), diz ekstansör (DİZE), diz fleksör (DIZF), dorsifleksör (DF), plantarfleksör (PF), invertör (I), evertör (E) kas gruplarının bileteral ölçümleri alındı. Her bir kas grubunun testi için, 5 saniyeden oluşan maksimum izometrik kontraksiyondan sonra 10 saniye dinlenme verilerek 3 defa tekrarlandı. ${ }^{21}$ Çıkan sonucun ortalaması alınarak normalizasyon işlemi için vücut ağırlığına bölündü.

\section{Asimetri Yüzdesinin ve Kas Kuvveti Oranlarının Hesaplanması \\ 3 tekrarlı maksimum izometrik} kontraksiyon değerlerinin ortalamaları alındıktan sonra değerlerin normalize edilmesi için vücut ağırlığına bölündü. ${ }^{22}$ Sağ ve sol bacağın asimetri yüzdesi aşağıdaki formülle hesaplandı. ${ }^{23}$ Elde edilen değerin (-) olması sol tarafın daha kuvvetli olduğunu (+) olması ise sağ tarafin daha kuvvetli olduğunu göstermektedir. $\mathrm{Bu}$ formülün çalışmamızda çarpık dağılıma yol açması bir dezavantaj olarak sayılabilir.

$\left(\frac{\text { Sağ bacak }- \text { Sol bacak }}{\text { Sağ bacakta veya sol bacakta elde edilen maksimum değer }}\right) \times 100$
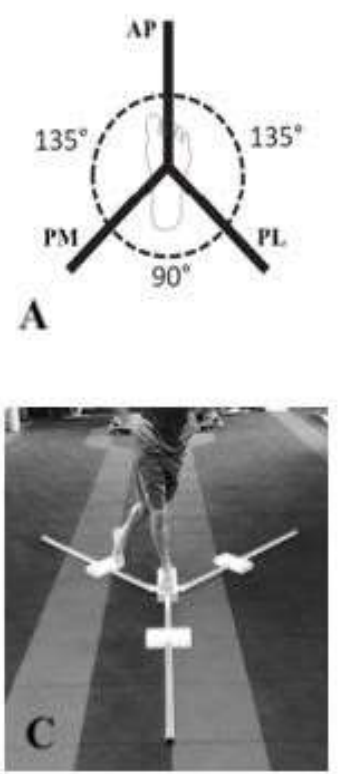

Şekil 1:Y Denge Testi.
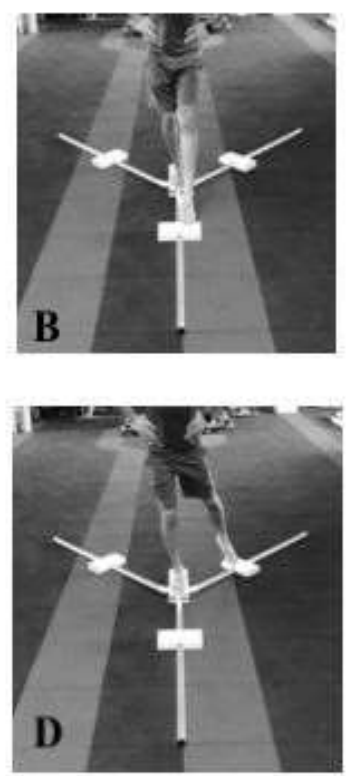
Ayrica agonist ve antagonist kasların oransal (ratio) değerleri kalça adduktör/kalça abduktör (KADD/KABD), kalça fleksör/kalça ekstansör (KF/KE), diz fleksör/diz ekstansör (DİF/DIZE), dorsifleksör/plantarfleksör (DF/DP) ve evertör/invertör (E/I) şeklinde hesaplandl.

İstatistiksel analiz

Verilerin istatistiksel analizlerinde SPSS 15.00 (SPSS Inc. Chiccago, IL, USA) programı kullanıldı. Bütün ölçümle belirtilen veriler aritmetik ortalama \pm standart sapma $(\mathrm{X} \pm \mathrm{SS})$ olarak ifade edildi. Tanımlayıcı analizler oyuncuların demografik verilerinin sunumu için kullanıldı. Parametreler arasındaki ilişki düzeyi Spearman Testi kullanılarak değerlendirildi. Sağ ve sol bacak değerleri arasındaki istatistiksel ilişki Wilcoxon İşaretli Sıra Testi ile değerlendirildi. Korelasyonun derecesi korelasyon katsayısına göre 0,10-0,39 arası düşük derecede korelasyon, 0,40-0,69 orta derecede korelasyon ve 0,70-0,89 arası yüksek derecede korelasyon şeklinde yorumlandı. ${ }^{24}$ Tüm istatistiklerde $\mathrm{p}$ anlamlılık değeri 0,05 olarak alındı. Çalışmamızın güç analizi GPower 3.1.9.2 programı ile yapıldı. Parametreler arasındaki ilişkinin belirlenmesinde uygulanan iki yönlü korelasyon analiziyle; $\alpha=0,05, n=20$, $\rho \mathrm{H} 0=0, \quad \rho \mathrm{H} 1=0,58 \quad(-0,44<\mathrm{r}<0,44) \quad$ sonuçlarına göre çalışmanın gücü 0,80 olarak belirlendi.

\section{BULGULAR}

Çalışmamıza dahil edilen oyuncuların yaşı $27,80 \pm 5,80$ yıl, boyu $1,79 \pm 0,07 \mathrm{~m}$, kilosu $77,87 \pm 8,49 \mathrm{~kg}$ ve vücut kütle indeksi $24,04 \pm 1,55$ $\mathrm{kg} / \mathrm{m}^{2}$ olarak bulundu. Tablo 1'de Y denge testinin anterior-posterior (AP), posteriormedial (PM) ve posterior-lateral (PL) yönlerindeki değerlerin bilateral farkları yer almaktadır. Groinbar sisteminde maksimal izometrik kas kontraksiyonu ile sağ ve sol taraf kıyasında sadece kalça abduktör ve adduktör kas grubu istatistiksel açıdan anlamlı olduğu bulundu $(\mathrm{p}<0,05)$ (Tablo 2). Tablo 3'de yer alan kas gruplarının oransal değerlerinden sadece dorsifleksör ve plantarfleksör oranı (DF/PF) istatistiksel açıdan anlamlı bulundu $(p<0,05)$. $\mathrm{AP}, \mathrm{PM}$ ve PL değerleriyle bilateral asimetri ve kas oranlarıyla yapılan korelasyon analizinin anlamlı sonuçları Tablo 4'de yer almaktadır. Bilateral asimetrinin anlamlı bulunduğu tek sonuç, plantar fleksör grubunun AP farkıyla olan pozitif yönlü korelasyonudur $(p=0,038$, rho=0,466). AP farkın $4 \mathrm{~cm}$ 'den büyük olduğu risk durumunda, bilateral asimetri ve kas oranıyla yapılan analizden sadece bilateral kalça adduktör ve kalça abduktör oranı (KADD/KABD) anlamlı bulundu $(\mathrm{p}<0,05)$ (Tablo 5).

Tablo 1: Y Denge Testi değerlendirme sonuçları ( $\mathrm{N}=20)$.

\begin{tabular}{lc}
\hline & $\mathrm{X} \pm \mathrm{SD}$ \\
\hline Anterior-posterior fark & $2,20 \pm 2,02$ \\
Posterior-medial fark & $4,95 \pm 4,20$ \\
Posterior-lateral fark & $2,95 \pm 2,96$ \\
\hline
\end{tabular}

\section{TARTIŞMA}

Çalışmamızın sonuçlarına göre, yaş ortalaması 27,8 yıl olan süper lig takımının oyuncularında $\mathrm{Y}$ denge testinde yönler arası farklılıklarda en fazla posterior-medial (PM) yönünde bulunmuştur. Stiffler vd. yaptığı çalışmadaki verilere benzer şekilde PM ve PL yönlerindeki farklar AP yönündekinden daha yüksek çıkmıştır. ${ }^{25}$

Sağ ve sol tarafin maksimal izometrik kas testine baktığımızda, kalça abduktör ve adduktör kas gruplarının dışında her iki taraf için kuvvet değerleri benzerdi. Kas oranlarının değerlendirildiği durumda sadece dorsifleksör ve plantarfleksör (DF/PF) kas oranı sağ ve sol taraf arasında istatistiksel açıdan farklı bulundu. Elde ettiğimiz verilere benzer şekilde, güncel çalışmalar da dominant bacak ile diğer bacağın arasında önemli bir farklılık olmadığını göstermektedir. ${ }^{26,27}$

Çalışmamızda her iki ayak bileği dorsifleksör ve plantar fleksör kas grupları arasındaki oran (DF/PF) ile denge testinde anterior-posterior (AP) bilateral fark arasında istatistiksel olarak anlamlı korelasyon bulundu. Sol tarafta güçlü negatif korelasyon saptanırken sağ tarafta orta derecede negatif korelasyon bulundu. DF/PF oranı 1'in altında değerler olduğu için kas değerleri birbirine yaklaştıkça oranın artması ve AP bilateral farkın azalması beklenir. Bu durumda ayak bileği yaralanmaları riskinin azalacağı 
söylenebilir. Ortaya çıkan bu sonucu destekleyen bir çalışmada, dengenin devamlılığı boyunca postüral salınımı minimize etmek için ayak bileği kaslarının aktivasyonu gerekli olduğuna vurgu yapılmıştır. ${ }^{28} \mathrm{Bu}$ sebeple, Y denge testi süresince dinamik dengeyi sürdürmek için vücut ağırlık merkezinin stabilitesini devam ettirmede ayak bileği plantar fleksör ve dorsi fleksörlerin rolü vardır. Literatürde, dinamik dengede değerlendirilen bacakların anterior yönde uzanma mesafelerindeki asimetri; sporun

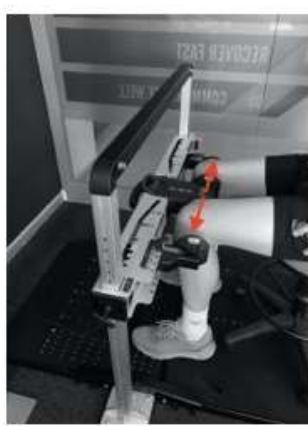

Kalça abduksiyonu

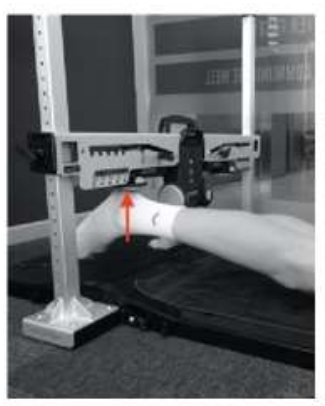

Kalça ekstansiyonu

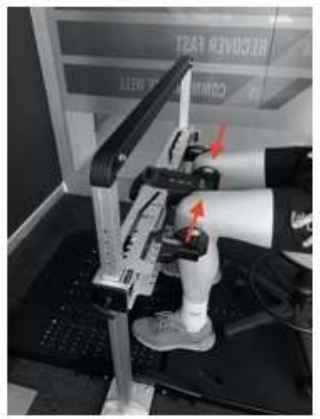

Kalça adduksiyonu

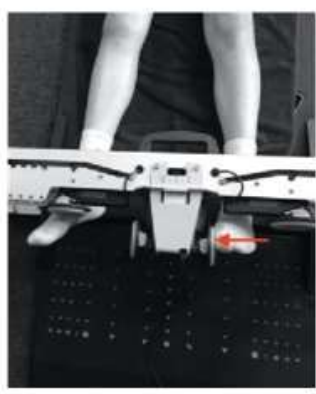

Ayak bileği inversiyonu Ayak bileği dorsifleks.

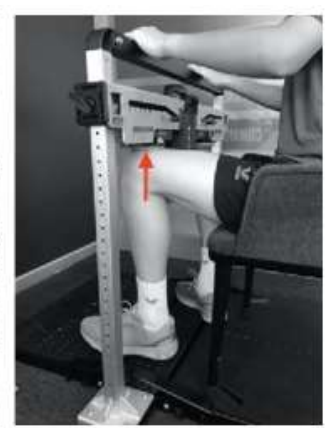

Kalça fleksiyonu

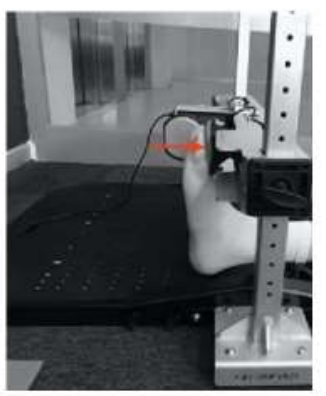

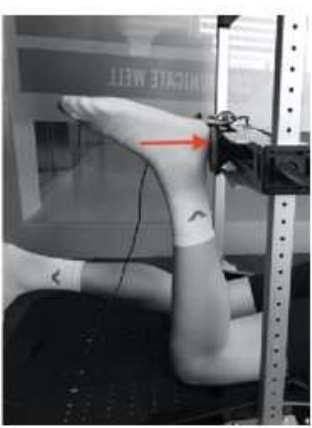

Diz fleksiyonu

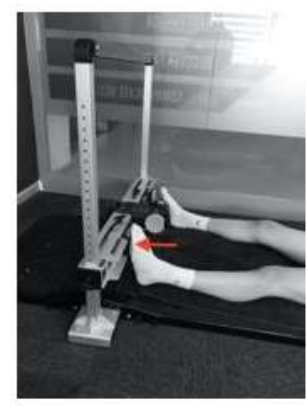

Ayak bileği plantar fl.

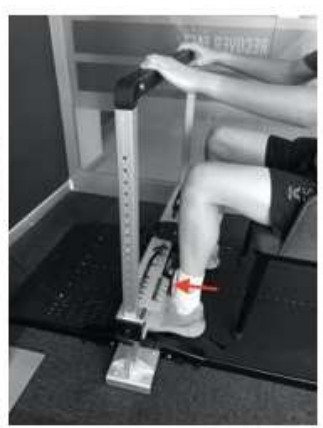

Diz ekstansiyonu

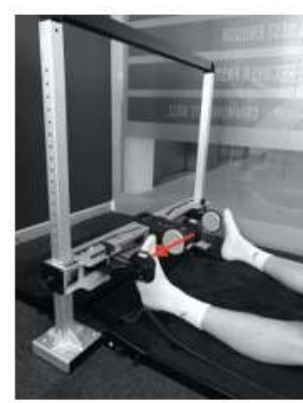

Ayak bileği eversiyonu

Şekil 2: Groinbar izometrik kas testleri.

Tablo 2: Groinbar İzometrik Kas Testi (Nm/kg, N=20).

\begin{tabular}{lccc}
\hline & Sol & Sağ & \\
& X \pm SD & X \pm SD & $p$ \\
\hline Kalça abdüktör & $4,33 \pm 1,12$ & $4,59 \pm 1,24$ & $0,00 *^{*}$ \\
Kalça addüktör & $3,55 \pm 0,93$ & $3,69 \pm 1,04$ & $0,030^{*}$ \\
Kalça fleksör & $4,50 \pm 1,52$ & $4,38 \pm 1,34$ & 0,627 \\
Kalça ekstansör & $2,27 \pm 0,81$ & $2,12 \pm 0,78$ & 0,052 \\
Diz fleksör & $2,24 \pm 0,63$ & $2,13 \pm 0,63$ & 0,108 \\
Diz ekstansör & $3,37 \pm 1,17$ & $3,18 \pm 0,79$ & 0,765 \\
Ayak bileği invertör & $1,34 \pm 0,40$ & $1,35 \pm 0,42$ & 0,520 \\
Ayak bileği evertör & $1,42 \pm 0,48$ & $1,45 \pm 0,40$ & 0,279 \\
Ayak bileği dorsifleksör & $2,73 \pm 1,16$ & $2,75 \pm 1,04$ & 0,940 \\
Ayak bileği plantar fleksör & $3,73 \pm 0,99$ & $3,56 \pm 0,97$ & 0,204 \\
\hline
\end{tabular}

${ }^{*} p<0,05$. 
Tablo 3: Kas gruplarının oransal değerleri.

\begin{tabular}{|c|c|c|c|}
\hline & $\begin{array}{c}\text { Sol } \\
X \pm S D\end{array}$ & $\begin{array}{r}\text { Sağ } \\
X \pm S D\end{array}$ & $\mathrm{p}$ \\
\hline Kalça adduktör / Kalça abduktör & $0,83 \pm 0,16$ & $0,81 \pm 0,15$ & 0,204 \\
\hline Kalça fleksör / Kalça ekstansör & $2,10 \pm 0,69$ & $2,17 \pm 0,58$ & 0,681 \\
\hline Diz fleksör / Diz ekstansör & $0,70 \pm 0,17$ & $0,68 \pm 0,14$ & 0,526 \\
\hline Dorsifleksör / Plantar fleksör & $0,73 \pm 0,22$ & $0,79 \pm 0,23$ & $0,048^{*}$ \\
\hline Evertör / İnventör & $1,07 \pm 0,21$ & $1,10 \pm 0,20$ & 0,433 \\
\hline
\end{tabular}

${ }^{*} \mathrm{p}<0,05$.

Tablo 4: Anterior-Posterior, Posterior-Medial ve Posterior-Lateral farkların kas gruplarına göre korelasyon analizi $(\mathrm{N}=20)$.

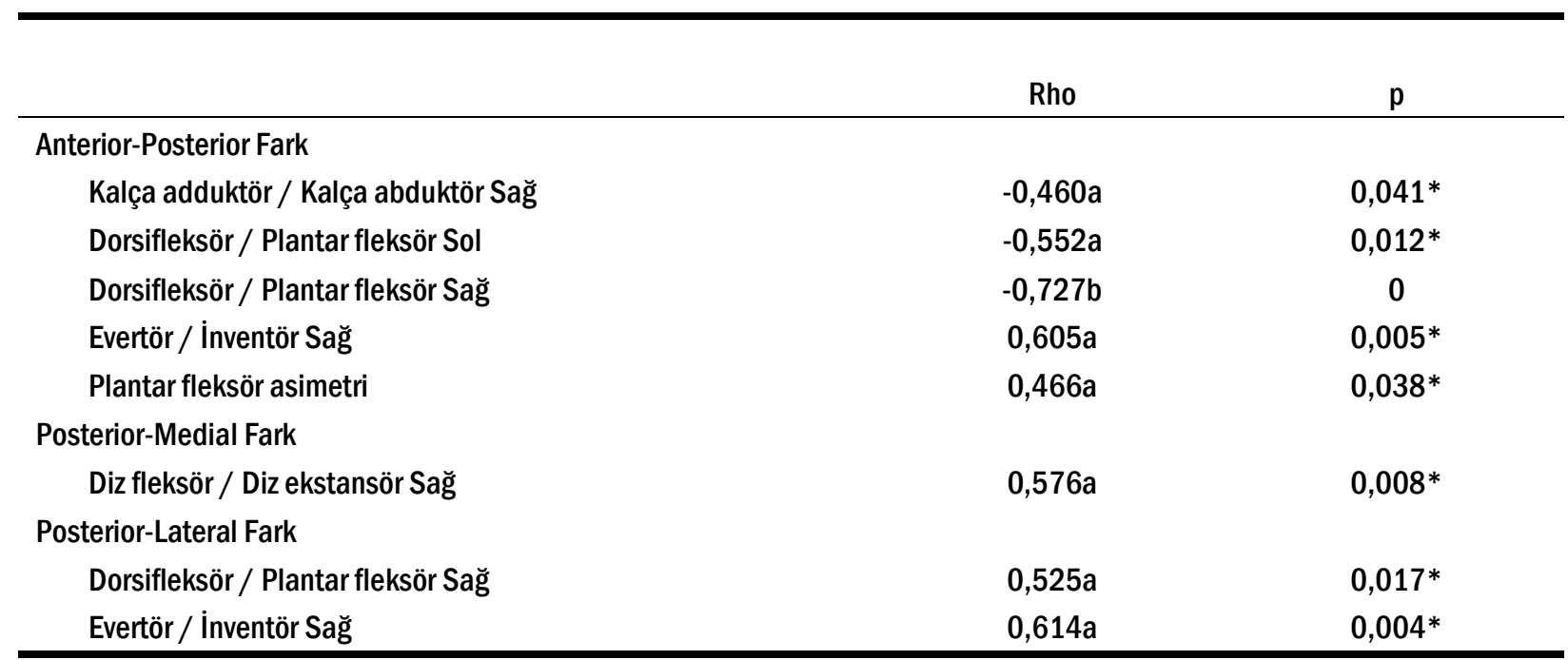

${ }^{*} p<0,05$. Rho: Spearman Testi. a: Rho: 0,40-0,69. b: Rho: 0,70-0,89.

Tablo 5: Anterior-Posterior riskin kas gruplarına göre korelasyon analizi (N=20).

\begin{tabular}{lcc}
\hline & Rho & $p$ \\
\hline Kalça adduktör / Kalça abduktör Sol & $-0,498 a$ & $0,026^{*}$ \\
Kalça adduktör / Kalça abduktör Sağ & $-0,595 a$ & $0,006^{*}$ \\
\hline
\end{tabular}

${ }^{*}$ p<0,05. Rho: Spearman Testi. a: Rho: 0,40-0,69.

içeriği, cinsiyet veya antrenman yükünden bağımsız olarak, temas içermeyen diz ve ayak bileği yaralanmass olasılığıyla ilişkili olduğu bulunmuştur. ${ }^{29}$ Plisky vd. yaptığı çalışmada, bacaklar arasındaki anterior uzanma farkının 4 cm'den daha fazla olması ayak bileği yaralanma riskini 2,5 kat artırdığı bulunmuştur. ${ }^{19,20}$

Birçok çalışmada, ayak bileğinin değişen pozisyonlarında kalça kasları da kalça ekleminin değişik açılarında dinamik dengeyi sürdürmek için devreye girdiğini saptamıştır. ${ }^{30,31} \mathrm{Bu}$ veriyi destekler biçimde, çalışmamızdaki AP farkın risk sınırını aştığı durumlarda; kalça abduktör ve adduktör kas grupları arasındaki oran (KADD/KABD) ile ayak bileği yaralanma riski açısından negatif yönde orta derecede korelasyon bulundu. Çalışmamızda KADD/KABD değeri 1'in altında 
değerler olduğu için bu kas grupları arasındaki farkın azalmasıyla oranın artması ve ayak bileği yaralanma riskinin azalacağını söyleyebiliriz. Yapılan EMG çalışmaları neticesinde, kalça abduktör ve adduktör kaslarının asıl görevinin dinamik hareket boyunca dengeyi sağlamak ve kalça eklem pozisyonunun korumak olduğu bulunmuştur. ${ }^{32-}$ 34 Benzer şekilde bayan futbol oyuncularında yapılan bir çalışmada postüral denge performansı ve kalça ekstansörünün maksimal izometrik kontraksiyonu arasında ilişki bulunmuştur. ${ }^{35} \mathrm{Bu}$ nedenle araştırmacılar, alt ekstremite izometrik kas kuvvetinin denge becerisi ve alt ekstremite yaralanmaları üzerinde önemli bir rolü olduğu sonucuna varmıştır. Bir başka çalışmada adolesan bayan futbol oyuncularında diz fleksör/ekstansör ve kalça abduktör kaslarının arasında ilişski saptanmıştır. Bununla birlikte alt ekstremite izometrik kuvvetinin denge becerisini etkilediğini; diz kaslarının kuvvetlenmesinin denge becerisini artırdığını ve alt ekstremite yaralanmalarını azalttığ

Çalışmamızda elde edilen sonuçlardan biri olan PF bilateral asimetrinin AP fark ile pozitif korelasyonu, PF kas grupları arasındaki asimetrinin artmasıyla AP farkının artması ve ayak bileği yaralanma riskinin artıracağı şeklinde yorumlanabilir. Fousekis vd. profesyonel futbol oyuncularında yaptığı bir çalışmada bilateral PF kuvvetin \%15'den fazla asimetrik olması durumunda ayak bileği yaralanmasına yol açabileceğini rapor etmiştir. ${ }^{37}$ Başka çalışmalarda futbolcularda bilateral alt ekstremite kuvvet farkının \%10 ve üzeri olması yaralanmalar için hazırlayıcı bir faktör olduğu belirtilmiş; \%15'den fazla kuvvet farkı olan oyuncularda zayif olan tarafin yaralanma oranının 2-6 kat daha fazla olduğu söylenmiştir. ${ }^{38}$

Genç elit futbolcularda izometrik kas kuvveti ve dinamik denge arasındaki ilişkiyi inceleyen bir çalışmada, izometrik kuvvetin Y denge testi performansina katkısı \%21,9 ile $\% 49,4$ olarak bulunmuştur. ${ }^{16}$ Literatürde, inversiyon ve eversiyon kuvvet defisitinin ayak bileği instabilitesiyle ilişkili olduğuna dair sonuçlar çelişkilidir. ${ }^{39} \mathrm{Bu}$ veriyle paralel bir şekilde, çalışmamızda yapılan istatistiksel analizle; sağ ayakta invertör ve evertör kas gruplarının oranı ile dinamik denge arasında ilişki saptanırken sol ayakta saptanmadı.
Çalışmamızda, bazı kas gruplarından sadece sağ/sol tarafın anlamlı çıkması veya korelasyonun negatif sonuçlanması, yeterli sayıda oyuncunun olmayışından ve oyuncuların dominant bacağa göre gruplandırılmamasından kaynaklanmış olabilir.

\section{Limitasyonlar}

Çalışmamızın birinci limitasyonu, kuvvet değerlendirmesinin kas gruplarına göre yapılmasıdır. Her bir kasin EMG sonucunu içeren daha detaylı asimetri değerlendirmesi yapılabilir. Çalışmamızda Y denge testindeki verilerin bacak uzunluğuyla beraber değerlendirilmemesi ikinci limistasyon olarak sayılabilir. Uçüncü limitasyon ise oyuncuların dominant/non-dominant ayak ayrımı yapılmadan çalışmaya alınmasıdır.

\section{Sonuç}

Çalışmamızda profesyonel futbolcularda alt ekstremiteye ait dorsi fleksör/plantar fleksör ve adduktör/abduktör kas oranlarına göre kuvvet değerlerinin birbirine yaklaşmasının dinamik dengeyi olumlu yönde etkilediği bulundu. Ayrıca bilateral plantar fleksör asimetrisinin dinamik denge üzerinde olumsuz etkisi saptandı. Klinik açıdan bu veri, kulüplerde sezon öncesi bu kas gruplarının değerlendirilmesiyle sezon içerisindeki olası ayak bileği yaralanmalarını önlemede ve performansın artırılmasında kullanılabilir. Bununla birlikte, dominant ayağa göre ve daha fazla oyuncu sayısıyla elde edilecek değerlerin sezon içerisinde ne tür yaralanmalara yol açabileceğini saptayan klinik açıdan daha değerli çalışmalar gelecekte yapılabilir.

Teşekkür: Yazarlar, İstanbul Başakşehir Futbol Kulübü Başkanı Sayın Göksel Gümüşdağ ve Yönetim Kuruluna, çalışmanın kulüp imkanlarıyla yapılmasına izin verdikleri için teşekkür ederler.

Araştırmacıların Katkı Oranı Beyanı: RS: Literatür araştırma, veri toplama, makale yazma; ET: Veri analizi/yorumlama; MGP: Çalışma tasarımı, literatür araştırma.

Çıkar Çatışması: Yok.

Finans: Yok.

Etik Onay: Bu araştırma protokolü Marmara Üniversitesi Sağlık Bilimleri Fakültesi Girişimsel Olmayan Etik Kurulu (sayı: 2018/11-15, tarih: 
29.11.2018) tarafindan onaylandı.

\section{KAYNAKLAR}

1. Kuss Rouissi M, Chtara M, Owen A, et al. Effect of leg dominance on change of direction ability amongst young elite soccer players. J Sports Sci. 2016;34:542-8.

2. Lockie RG, Schultz AB, Callaghan SJ, et al. The relationship between dynamic stability and multidirectional speed. J. Strength Cond. Res. 2016;30:3033-43.

3. Evangelos B, Georgios K, Konstantinos A, et al. Proprioception and Balance Training Can Improve Amateur Soccer Players Technical Skills. J. Phys. Educ. Sport. 2012;12:81-89.

4. Rahnama N, Lees A, Bambaecichi E. A comparison of muscle strength and flexibility between the dominant and non-dominant leg in English soccer players. Ergonomics, 2005; 48:1568-1575.

5. Fousekis K, Tsepis E, Vagenas G. Lower limb strength in professional soccer players: profile, asymmetry, and training age. J Sports Sci Med, 2010;9:364-373.

6. Behm DG, Drinkwater EJ, Willardson JM, et al. Canadian society for exercise physiology position stand: The use of instability to train the core in athletic and nonathletic conditioning. Appl Physiol Nutr Metab. 2010;35:109-12.

7. Agel J, Evans TA, Dick R, et al. Descriptive epidemiology of collegiate men's soccer injuries: National Collegiate Athletic Association Injury Surveillance System. 1988-1989 through 20022003. J Athl Train. 2007;42:270-277.

8. Yilmaz AK, Kabadayi M, Mayda MH, et al. The effects of isokinetic knee strength on the promptness of soccer players. J. Phys. Educ. Sport. 2017;3:114-123.

9. Rosch D, Hodgson R, Peterson TL, et al. Assessment and evaluation of football performance. Am. J. Sports Med. 2000;1:28-34.

10. Krespi M, Sporis G, Popovic S. Exponential versus linear tapering in junior elite soccer players: effects on physical match performance according to playing positions. Monten. J. Sports Sci. 2019;8:8-13.

11. Soderman K, Alfredson H, Pietila T, et al. Risk factors for leg injuries in female soccer players: a prospective investigation during one out-door season. Knee Surg. Sports Traumatol. Arthrosc. 2001;9:313-21.

12. Vargas VZ, Motta C, Peres B, et al. Knee isokinetic muscle strength and balance ratio in female soccer players of different age groups: a cross-sectional study. Phys Sportsmed. 2019;10:1080.

13. Erkmen N, Taskin H, Sanioglu A, et al. Relationships between balance and functional performance in football players. J Hum Kinet. 2010;26:21-9.

14. Van Dyk N, Bahr R, Whiteley $R$, et al. Hamstring and quadriceps isokinetic strength deficits are weak risk factors for hamstring strain injuries: A 4-year cohort study. Am J Sports Med. 2016;44:1789-1795.

15. Muehlbauer T, Gollhofer A, Granacher U. Association of balance, strength, and power measures in young adults. J Strength Cond Res. 2013;27:582-9.

16. Moktar T, Mehdi R, Nicola LB, et al. Dynamic balance ability in young elite soccer players: implication of isometric strength. J Sports Med Phys Fitness. 2018;58:414-20.

17. Cameron JP, Teralyn KD, Emily HG. Systematic review the reliability of the star excursion balance test and lower quarter $\mathrm{Y}$ balance test in healthy adults: A Systematic Review. Int J Sports Phys Ther. 2019;14:683.

18. Shaffer SW, Teyhen DS, Lorenson CL, et al. Ybalance test: a reliability study involving multiple raters. Mil Med. 2013;178:1264-70.

19. Butler RJ, Lehr ME, Fink ML, et al. Dynamic balance performance and noncontact lower extremity injury in college football players: an initial study. Sports Health. 2013;5:417-22.

20. Plisky PJ, Rauh MJ, Kaminski TW, et al. Star excursion balance test as a predictor of lower extremity injury in high school basketball players. J Orthop Sports Phys Ther. 2006;36:911-9.

21. Gauthier D, Sylvain G, Mickael B. Test-retest reliability of a hip strength assessment system in varsity soccer players. Phys Ther Sport. 2019;37:138-143.

22. Goran M, Nejc S, Jelena P, et al. Adductor muscles strength and strength asymmetry as risk factors for groin injuries among professional soccer players: A prospective study. Int. J Environ Res Public Health. 2020;17:4.

23. Impellizzeri FM, Rampinini E, Maffiuletti N, et al. A vertical jump force test for assessing bilateral strength asymmetry in athletes. Med Sci Sports Exerc. 2007;39:2044-2050.

24. 24-Schober P, Boer C, Schwarte LA. Correlation coefficients: Appropriate use and interpretation. Anesth. Analg. 2018;126:17631768.

25. Stiffler MR, Bell DR, Sanfilippo JL, et al. Star excursion balance test anterior asymmetry is associated with injury status in division I collegiate athletes. J Orthop Sports Phys Ther. 2017;47:339-346. 
26. Stiffler MR, Sanfilippo JL, Brooks MA, et al. Star Excursion Balance Test performance varies by sport in healthy division I collegiate athletes. J Orthop Sports Phys Ther. 2015;45:772-780.

27. Cug M, Wikstrom EA, Golshaei B, et al. The effects of sex, limb dominance, and soccer participation on knee proprioception and dynamic postural control. J. Sport Rehabil. 2016;25:31-39.

28. Johnson TK, Woollacott MH. Neuromuscular responses to platform perturbations in powerversus endurance-trained athletes. Percept Mot Skills. 2011;112:3-20.

29. Smith CA, Chimera NJ, Warren M. Association of y balance test reach asymmetry and injury in division I athletes. Med Sci Sports Exerc. 2015;47:136-141.

30. Horak FB, Nashner LM. Central programming of postural movements: adaptation to altered support-surface configurations. J Neurophysiol. 1986;55:1369-81.

31. Winter DA. Human balance and posture control during standing and walking. Gait Posture. 1995;3:193-214.

32. Neptune RR, Wright IC, Van Den Bogert AJ. Muscle coordination and function during cutting movements. Med Sci Sports Exerc. 1999;31:294-302.

33. Havens KL, Sigward SM. Joint and segmental mechanics differ between cutting maneuvers in skilled athletes. Gait Posture 2015;41:33-8.
34. Suzuki Y, Ae M, Takenaka S, et al. Comparison of support leg kinetics between side-step and cross-step cutting techniques. Sports Biomech. 2014;13:144-53.

35. Palmer TB, Hawkey MJ, Thiele RM, et al. The influence of athletic status on maximal and rapid isometric torque characteristics and postural balance performance in division I female soccer athletes and non-athlete controls. Clin Physiol Funct Imaging. 2015;35:314-22.

36. Inoue $\mathrm{Y}$, Otania $\mathrm{Y}$, Naruse $\mathrm{S}$, et al. Relationships between lower-extremity muscle strength and the modified star excursion balance test in adolescent female soccer players. Rigakuryoho Kagaku. 2015;30:155.

37. Fousekis K, Tsepis E, Vagenas G. Multivariate isokinetic strength asymmetries of the knee and ankle in professional soccer players. J Sports Med Phys Fitness. 2010;50:465-474.

38. Nohutlu OE. Profesyonel futbolcularda diz yaralanmalarını oluşturan risk faktörlerinin analizi. [Master Thesis]. Ankara: Hacettepe University: 2009.

39. Sabine D, Martin A. The influence of sensorimotor training modalities on balance, strength, joint function, and plantar foot sensitivity in recreational athletes with a history of ankle sprain: A randomized controlled pilot study. Int $J$ Sports Phys Ther. 2018;13:993-1007. 